\title{
Homossexualidade e Corpos Estereotipados
}

\author{
La homosexualidad y Cuerpos Estereotipados \\ The homosexuality and bodies stereotyped
}

\section{Larissa Pinto Martins'; Ana Valéria Goulart Dos Santos²; Bel. Rylanneive Leonardo Pontes Teixeira ${ }^{3}$}

\begin{abstract}
Resumo
O presente artigo visa abordar a forma com a qual é apresentada a imagem de pessoas homossexuais e homoafetivas através de seus corpos, e, sendo estes, objetos políticos, passam, portanto, a ser enquadrados como masculinizados ou efeminados. Estas definições sobrecaem, respectivamente, em cima de Lésbicas e Gays, o que, infelizmente, resulta na formação de um imaginário social equivocado que acaba não correspondendo a muitas realidades e limitando suas identidades a uma imagem restrita. Sabe-se que em decorrência dessa falta de representatividade, nasce o (pré)conceito como fruto de uma ignorância que desconhece a verdadeira realidade. Nossa proposta é, então, desmistificar essa imagem já petrificada, mostrando como se estrutura a formação de estereótipos, para que, dessa forma, venhamos a colaborar com uma sociedade livre de padrões que enclausure pessoas, ao passo que, sendo estas singulares, não podem ser classificadas.
\end{abstract}

Palavras-Chave: Corpos; estereótipos; homossexuais; imagem; patriarcado.

\section{Resumen}

El presente artículo busca abordar la forma en que se presenta la imagen de personas homosexuales y homoafetivas a través de sus cuerpos, y, siendo estos, objetos políticos, pasan, por lo tanto, a ser encuadrados como masculinizados o afeminados. Estas definiciones sobrecaem, respectivamente, en cima de Lésbicas y Gays y, lo que, infelizmente, resulta en la formación de un imaginario social equivocado que acaba no correspondiendo a muchas realidades y limitando sus identidades a una imagen restricta. Sabe-se que como resultado de esta falta de representatividad, nasce el (pre)juicio como fruto de una ignorancia que desconoce la verdadera realidad. Nuestra propuesta es, entonces, desmitificadora de esta imagen ya petrificada, mostrando cómo se estructura la formación de estereotipos, para que, de esta forma, lo haremos de colaborar con una sociedad libre de normas que encierre personas, a lo paso que, siendo estas singulares, no pueden ser clasificadas.

Palabras claves: Cuerpos; estereotipos; homosexuales imagen; patriarcado.

\section{Abstract}

The present article search approach the form on what presents the image of gay people and homosexual through their bodies, and, these being, political objects, pass, therefore, to be framed as masculinized or effeminate. These settings fall, respectively, on Lesbians and Gays and, which unfortunately, results in the formation a misguided social imaginary that just not corresponding many realities and limiting their identities a restricted image It is known that as a result of this lack of representativeness, born prejudice as the fruit of ignorance that ignores reality. Our proposal is then demystify this image already petrified, showing how to structure the

\footnotetext{
${ }^{1}$ Graduanda em História; Universidade Federal do Pampa - Unipampa; Jaguarão, Rio Grande do Sul, Brasil; larissa.pmartins@yahoo.com.br.

${ }^{2}$ Graduanda em Letras Português e Espanhol; Universidade Federal do Pampa - Unipampa; Jaguarão, Rio Grande do Sul, Brasil; anavaleriagoulart@gmail.com.

${ }^{3}$ Bacharel em Gestão de Políticas Públicas, mestrando em Estudos Urbanos e Regionais; Universidade Federal do Rio Grande do Norte - UFRN; Natal, Rio Grande do Norte, Brasil; pontesrylanneive@ gmail.com.
} 
formation of stereotypes, so that in this way, can cooperate with a free society standards that people enclosure, whereas, these being unique, they cannot be classified.

Keywords: Bodies; stereotypes; homosexuality; image; patriarchate.

\section{Introdução}

Quando falamos em corpo, muitas pessoas associam a ciências biológicas, células, sistemas, músculos; mas o corpo é muito mais do que biologia, é também um objeto social que se torna mutável - à medida que seja necessário- por nós ou pela cultura na qual estamos inseridos, pois a própria sociedade em que vivemos tem influência sobre nossos copos, e este fato é tão naturalizado que muitas vezes não o percebemos. Nesse sentido, de acordo com Foucault (2006 apud BOLSONI, 2012), “o corpo é ao mesmo tempo uma massa, um invólucro, uma superfície que se mantém ao longo da história. [...], isto é, matéria, literalmente um lócus físico e concreto. Essa matéria física não é inerte, sem vida”. Desta forma, o corpo consiste em um "objeto" revestido, o qual é modificado em conformidade com as normas vigentes da sociedade e/ou tempo no qual está inserido.

Goellner (2008) coloca o corpo como sendo mais do que um conjunto de células e que, portanto, não são as semelhanças biológicas que nos definem, mas fundamentalmente, os significados culturais e sociais que a ele são atribuídos. Sendo assim, o que enquadram lésbicas e gays, enquanto homossexuais, além das suas orientações sexuais, são, também, as atribuições sociais a eles incumbidas, fazendo com que os mesmos se intitulem como Homossexuais e sejam percebidos pela sociedade de igual forma.

Partindo da teoria da biopolítica, da noção de corpo como construção social e levando em consideração as ideias do filósofo francês Michel Foucault, iremos trabalhar, neste artigo, a representação imagética dos homossexuais, questionando sua veracidade a partir de estereótipos que a sociedade impõe a mulheres lésbicas e homens gays. Sendo assim, o objetivo central deste trabalho é abordar como é apresentada à sociedade a imagem de pessoas homossexuais e homoafetivas através de seus corpos, e, entendendo os corpos como objetos políticos, como eles passam a ser enquadrados como efeminados ou masculinizados.

A biopolítica torna o corpo modelável à medida do contexto em que se encontra, através de biopoderes. Um exemplo clássico de biopoderes é a relação de gênero na qual os homens historicamente são quem ditam o poder sobre os corpos das mulheres, legitimando-se cada vez mais, dessa forma, no patriarcado e dando continuidade a ele. Neste mesmo sentido é que os corpos homossexuais serão moldados, o homem, heterossexual, usa de seu poder 
patriarcal para moldar os estereótipos e difundi-los na sociedade, demarcando como devem ser os homossexuais.

Enquanto a disciplina se dá como anátomo-política dos corpos e se aplica essencialmente aos indivíduos, a biopolítica representa uma "grande medicina social" que se aplica à população a fim de governar a vida: a vida faz, portanto, parte do campo do poder. (REVEL, 2005, p. 27)

Sendo o Corpo um objeto moldável pelo poder, o presente artigo demonstra as formas na qual os homossexuais foram modelados pela sociedade heteronormativa com seu (pré)conceitos e estereotipações, o que acabou por mistificar os homossexuais e não corresponder a realidade dos mesmos em sua grande parte.

A luta pela desmistificação dos corpos faz com que a sexualidade seja um problema político. Os corpos de homossexuais representa então um marco da resistência, uma vez que vai contra ao que já está estabelecido pelo poder patriarcal. Isto é uma das vertentes da biopolítica, esta resistência e existência fazem com que aconteçam mudanças e desestruturem os pilares patriarcais e heteronormativos.

Entendemos a importância de fazer uma breve explicação do que seria o patriarcado para que então possamos entender como se da, ainda hoje, a criação de estereótipos e (pré)conceitos. O Patriarcado tem como definição ideológica a supremacia do homem nas relações sociais. O termo vem do latim pater, usado durante a antiguidade e significava a figura do pai, o provedor e líder da família, muito usado com uma conotação de preponderância do homem perante a sociedade. A principal característica do patriarcado é o homem como centro da organização social, ao qual todos os demais membros deviam obediência, quase uma espécie de servidão, isentavam-se desse dever, os demais patriarcas.

Quando nos referimos ao patriarcado neste artigo, falamos apenas do que é presente na sociedade ocidental. Embora, o oriente também sofra com o patriarcado, ele se dá em uma conjuntura diferente da nossa realidade.

\section{Estereótipos: uma análise sobre os corpos de mulheres lésbicas e homens gays.}

O corpo é uma construção coletiva, sendo assim, apresenta além de estruturas biológicas, marcas de influências sociais. É constituído por tudo que o rodeia: cultura, religião, forma de vestir, gesticular, falar, andar etc.. Seguindo essa linha de raciocínio, falar de corpo é falar também de identidade, logo, é isso que está problematizado aqui, pensando que, na maioria das vezes, essa tal identidade é forjada de uma maneira violenta pela sociedade em que vivemos. Os corpos de homossexuais são um exemplo claro desta construção promovida pela sociedade. 

e-ISSN 2016/Atual: 2525-7870 | e-ISSN 2015/2016: 2447-018X

Lésbicas e Gays, por fugirem dessa "normalidade" pré-estabelecida, centrada no fato de apenas a heterossexualidade poder ser considerada normal, acabam por ser estereotipados, em virtude de acreditar-se que o homem ao ser gay naturalmente perde algo que é de estrema importância para a manutenção do patriarcado, a sua virilidade masculina, e passa, obrigatoriamente, a conter traços "femininos", se não for dessa forma, ele não é reconhecido como gay.

O mesmo acontece com as mulheres lésbicas, que, na visão de muitas pessoas, só são vistas como lésbicas quando possuem traços mais "masculinos", pois se forem "femininas", o que, segundo o patriarcado é obrigação de toda mulher, não são rotuladas como lésbicas, ou se são, perdem a sua autenticidade, pois, se assumem-se lésbicas perante a sociedade, no pensamento preconceituoso, a conduta desta mulher tem a única e exclusiva pretensão de chamar atenção, ou provocar aos homens. Posto que, na lógica machista, o homem hétero, é o centro de todas as atenções, como se o mundo todo girasse em torno dele e por causa dele. Fala-se aqui em machismo e não em patriarcado, porque o machismo é um sintoma muito forte de uma sociedade estruturada pelo patriarcado.

Por conseguinte, não é surpresa que toda sociedade que sofre com o machismo, seja por decorrência do patriarcado presente nas relações de poder, seja na família, no governo, ou no trabalho.

Levando isso em consideração, conforme o pensamento anterior, obviamente, uma mulher lésbica feminina, não pode ser legitimamente homossexual, ela é apenas um objeto sexual. Primeiro por ser mulher, segundo pela sua orientação sexual ser para a saciação do desejo masculino.

Contudo, as mulheres lésbicas e os homens gays que seguem uma linha heteronormativa, raramente são enquadrados em algum estereótipo que seja pejorativo. Isto se da pelo fato de que ao seguir uma conduta padronizada e largamente difundida pela sociedade, não são vistos enquanto homossexuais, e isso também acaba por deturpar suas identidades.

Para entender melhor a questão de identidades que tanto citamos neste artigo, recorremos ao teórico cultural e sociólogo Stuart Hall. Compreendemos a partir da leitura do capítulo III do livro "Identidade e diferença: a perspectiva dos estudos culturais", o que seria a identidade e a diférrence.

A identidade seria algo importante para a constituição de um sujeito ou até e de uma nação como unidade de grande relevância representativa para si e perante os outros, sejam 
outras nações ou outras pessoas, com a identidade formada, podemos nos reconhecer como indivíduos concretos e completos, mas sempre em evolução e formação.

Pensando nisso, reconhecemos um perigo e nos preocupamos muito com ele, de se na fase de formação basilar dessa identidade, estes preconceitos afetarem de uma forma tão forte e violenta a pessoa, que ela acabe por internalizar essas questões. Isto afetaria a saúde mental desta pessoa, pois se reconhece de uma forma, mas para a sociedade e para si mesma nega essa identidade, já que está em contradição com o seu dever como homem ou mulher, de ser e se portar no mundo.

Mas há um, porém, também devemos levar em consideração a diférrence, que está intimamente relacionada com a identidade. A diférrence seria as particularidades existentes dentro de uma mesma identidade. Como um exemplo simples, pensamos em um grupo de torcedores do mesmo time de futebol, essa é a sua identidade (torcedores daquela equipe), a diférrence seriam os elementos que os diferenciam, por exemplo, na torcida existem crianças, adultos e idosos, dentre uma variedade enorme de pessoas, logicamente. Vale lembrar que cada uma dessas subclassificações, formam identidades, que por sua vez, dentro delas, existem suas diférrences. Dentro da identidade "criança", existem as crianças de cabelos castanhos, ou de faixa etária de 8 (oito) a 12(doze) anos, ou que se identificam por serem deficientes físicas, e, dentro da deficiência, que seria mais uma possível identidade, existem outras diférrences, como o tipo de deficiência de cada, as particulares dentro dessa mesma subclassificação, como o sexo, entre inúmeras outras que possamos contar, e assim por diante, é que se dá essa lógica de pensamento.

Dessa forma, pensamos que mesmo dentro da identidade homossexual, existem inúmeras diférrences, cabe ao leitor deste artigo, refletir sobre essa questão e verá que é impossível conseguir colocar todas essas pessoas dentro de caixinhas.

Os moldes aos quais nos referimos são criados para a manutenção do poder do patriarcado, fazendo com que a mulher sempre seja submissa ao homem, e nunca possa sair dessa posição, engessando-a socialmente e psicologicamente para sempre ali. Se uma mulher desejar ser livre para amar e se relacionar com outra mulher, estará quebrando com essa regra, e dessa forma enfraquecendo o patriarcado, o que, como tudo que vai contra ao patriarcado é algo feito com muita dificuldade e sofrimento para quem quer exercer seu direito de ser livre.

Com o homem acontece o mesmo, pois ao querer relacionar-se com outro homem, estaria perdendo seu privilégio natural, concedido por simplesmente ter nascido com o órgão genital biologicamente masculino, de possuir sua masculinidade/virilidade, o que o excluiria da classe dominadora. 

e-ISSN 2016/Atual: 2525-7870 | e-ISSN 2015/2016: 2447-018X

Sendo assim, cria-se uma heteronormatividade para que estejam presentes até mesmo em relações homossexuais, os papéis masculino e feminino (dominador e dominada ou dominador e submissa), colocamos a desinência de gênero "a" nas palavras dominada e submissa, por justamente este ser, congruente com essa normativa heterossexual, o papel da mulher, enquanto ao homem cabe ser sempre o dominador. Mesmo tratando-se de dois homens, ou de duas mulheres, a heteronormatividade imposta a estas relações faz com que a mulher masculinizada torne-se o dominador, papel do homem, perante sua parceira, enquanto o gay efeminado torne-se a submissa -ou- dominada da relação.

No entanto, o que muitas vezes passa despercebido é que estes estereótipos fazem com que se crie uma falsa imagem sobre os homossexuais, uma imagem que priorize relações heteronormativas, e não relações homoafetivas. Ademais, se pensarmos também nas relações heterossexuais, ela os aprisiona de forma parecida, pois o homem jamais poderá sair do seu papel, mesmo que possua uma namorada que seja mais impositiva, ou simplesmente mais brincalhona e expressiva, a sociedade que o rodeia, irá ridicularizá-lo, pois esse fato que é tão normal torna-se, dentre sua roda de amigos, motivo de chacota. Uma vez que o homem é quem deve fazer piadas, ao passo que a mulher, cabe rir delas. Esta é uma ideia que é baseada no patriarcado ocidental, onde não pode haver essa inversão de papeis, ou seja, a mulher jamais poderá ser ou assumir algum papel que seja tido como superior ao homem, mesmo que se ao analisarmos essa situação, não haja superioridade nenhuma, há apenas, tipos de personalidades diferentes.

Dentre as preconcepções existentes sobre lésbicas, escolhemos duas para exemplificar e melhor desenvolver, como se dá o (pré)conceito na visão heterossexual. Logo após, exemplificaremos como é distribuído a estereotipação de lésbicas pra lésbicas.

Primeiramente, ao falar em lésbicas, muitas pessoas pensam naquela mulher "masculinizada", que se veste com roupas ditas masculinas, usam cabelo curto, e não possuem, ou pelo menos não prezam, pela sua feminilidade. Este é um padrão básico, bastante disseminado, atribuído a mulheres que optam por não submeter-se a regras que a sociedade impõe para as mulheres de ser femininas. Este estereótipo, aplicado às lésbicas, acaba por respingar, também, em mulheres heterossexuais que não são tão atentas aos padrões de feminilidade preestabelecidos na e pela sociedade. O que reforça a contradição destes estereótipos, que segue um padrão estético social, não importando necessariamente a sexualidade ou individualidade.

Outro estereótipo é o da lésbica feminina fetichizada. Este, além de colocar a sexualidade da lésbica em dúvida, por não ser uma mulher masculina, é também objetificada 

e-ISSN 2016/Atual: 2525-7870 | e-ISSN 2015/2016: 2447-018X

como fetiche sexual masculino, onde só poderá ser lésbica para satisfazer a um homem, sem considerar que em uma relação homossexual feminina não existe a necessidade da presença de um.

Este estereótipo, faz com que muito do (pré)conceito com lésbicas sejam mascarados. Cria-se uma visão de aceitação perante a sociedade, uma vez que, a lésbica feminina, segue o mesmo padrão da mulher hétero, contudo, esta aceitação se da apenas pelo fato de que o homem hétero possui um fetiche sexual sobre as lésbicas. Sendo assim, a imagem de um casal homoafetivo lésbico torna-se menos impactante do que a imagem de casais homoafetivos gays, já que estes fogem daquilo que os homens héteros querem possuir e tornam-se ofensivos, pois representam a perda da virilidade, a qual o homem culturalmente já nasce possuindo-a, o que legitimaria a sua superioridade patriarcal.

A eficácia desta camuflagem de aceitação torna-se um pilar para o que aconteçam estupros "corretivos", uma vez que pelo fato de ser feminina, a sociedade acaba duvidando da sexualidade da mulher lésbica e cria-se o pensamento de que "só ainda não encontrou o homem certo" ou "o homem que faça direito", este tipo de pensamento alastrado dentro de uma sociedade, faz com que muitos homens acreditem que o estupro corretivo seja coerente e que não haverá grandes punições em caso de denuncia, pois a sociedade compartilha da mesma concepção. Sabendo da força deste pensamento no meio em que vivemos, a grande maioria de lésbicas e gays acabam por não fazer a denuncia por medo de sofrer perseguição ou até mesmo novos abusos no local de denúncia, pois sabe-se que até mesmo os profissionais que deveriam lhes dar seguranças compactuam do mesmo ideal.

O estupro corretivo não limita-se apenas a mulheres lésbicas, mas se estende também aos homens gays, uma vez que os dois são considerados como desvios da normatividade heterossexual. O homem hétero se sente, então, no direito de abusar de gays, pois os mesmos, por já gostar de homens, devem, obrigatoriamente, fazer sexo com o homem que quiser transar com ele, independente da sua vontade. Os mesmos abusadores acham que têm o dever de ensinar as mulheres "a gostar de homem", uma vez que o poder patriarcal lhe confere a responsabilidade de ser o senhor de uma mulher, lhe ensinando tudo o que deve ser ensinado, como gostar de homens, por exemplo.

Entendemos por estupro corretivo, o estupro que é legitimado pelo pensamento de que esse ato irá corrigir a postura de uma pessoa, e que com isso, ela irá aprender alguma lição que seria boa para si. Com isso, além do que já expomos, as denuncias acabam por não ser feitas, em decorrência do medo, da repercussão social, da repressão familiar, ou do próprio pensamento da vítima de que na realidade ela de certo modo "merecia" a violência sofrida. 
Voltando aos estereótipos, há também outros tipos criados até mesmo dentro da comunidade LGBT, a qual divide as lésbicas em várias subcategorias. Não se aprofundando nessa discussão, traremos alguns exemplos, justamente para mostrar o que o corpo do artigo nos fala, que estas divisões feitas dentro da comunidade, estão diretamente ligadas a heteronormatividade que acaba por estar presente, mesmo que inconscientemente, no nosso cotidiano,

Trazemos apenas três tipos, como corpus de análise, dentre os mais diversos difundidos dentro da comunidade LGBT. Começaremos falando das Ladys, nomenclatura criada para diferenciar aquelas mulheres extremamente feminina, que são vistas assim, por estar sempre maquiada, de vestido, salto alto, etc., o tipo de aparência que não é normalmente esperada, ou estereotipada enquanto lésbicas pela sociedade.

O oposto das Ladys seriam as Bofinhos, que consistem naquelas que não optam pela feminilidade, as que são consideradas masculinas, também conhecidas como "Caminhoneiras", por ter o cabelo mais curto, não usar maquiagem, e andar com roupas ditas masculinas. Estas, na regra heteronormativa, assumiriam o papel de "homem da relação". Contudo, no meio LGBT, são elas que problematizam a questão de que não é por se vestirem e portarem-se de um jeito "masculino" que seriam um homem. O fato de assumirem suas masculinidades não interfere nada em seu gênero, essa é uma outra questão que tem a ver com a cis/transgeneridade que poderá ser explorado em uma próxima oportunidade, mas que por enquanto não é o foco deste trabalho.

Entre estes dois estereótipos criados dentro da comunidade LGBT, surgem as "Meio Termo" que seriam as que aparentemente não se caracterizam como femininas, no entanto, também não são masculinas. Seriam aquelas que misturam roupas ditas femininas com masculinas, que tem traços e expressões, tanto de um quanto de outro. Um exemplo claro seria uma mulher que usa maquiagem e opta pelo tênis em vez de salto alto, que ao escolher o que vestir, pode querer sair de vestido ou camisa, ou quem sabe usa-los juntos, com ou sem maquiagem, com ou sem salto alto, exibindo sua mescla natural de feminilidade e masculinidade.

Os gays também passam por situações de triagens sociais ocorrendo, principalmente, quando pensamos num homem gay como sendo aquele efeminado, seja na fala, no comportamento, no modo de se vestir, etc. Isso está intimamente relacionado ao fato de assimilar um gay à feminilidade. Esses aspectos são elementos característicos do preconceito presente na sociedade e em sua população, já que não reconhecem, enquanto gays, homens que não possuem traços femininos. 
O preconceito, diretamente relacionado ao estereótipo, se faz presente também no "mundo" gay quando há uma segregação entre os "másculos" e os "femininos", onde muitos dos masculinizados não se relacionam com os efeminados, por considerá-los inferiores em razão da especial "condição feminina” que lhes conferem. Nesse sentido, podemos caracterizar alguns dos estereótipos conferidos aos gays:

Os efeminados, conhecidos como "Afeminados", são aqueles que não apresentam maneiras viris, ou modos considerados másculos característicos de um homem hétero. Vestem-se com roupas ditas femininas ou calças apertadas por exemplo. São mais delicados e vaidosos, componentes sociais e culturais característico de uma mulher padronizada pelo patriarcado.

Em contrapartida, há os homens gays "masculinizados", consistem naquele que tem todos os atributos de um homem heterossexual, seja na fala, no jeito de andar e vestir. Homens que ao olhar sem muita atenção, passa-se facilmente por hétero.

Outro termo muito utilizado entre o homens gays é o de "Urso" que seriam os gays que tentem a possuir corpo peludo e barba, tendo um porte grande na maioria dos casos. Os Ursos também são conhecidos por manterem uma atitude mais viril, ou bruta.

Ao trabalhar com sexualidade e gênero, acabamos limitando o presente artigo entre lésbicas e gays para desmistificar e apontar os estereótipos criados pela sociedade. Mas quando nos referimos a homem ou mulher, estamos falando também daqueles que não nasceram com a genital do seu gênero, o que são chamados de transexuais. Ainda há um enorme tabu envolta de lésbicas e gays transexuais, pois a ideia de que o gênero e a sexualidade são a mesma coisa ainda é bastante difundida perante a sociedade, sendo assim, muitas pessoas não conseguem entender que uma mulher trans pode ser lésbica ou que um homem trans possa ser gay. Ou seja, eles sofrem com a mesma estereotipação, ou desvalorização justamente pelo fato de a sociedade não conseguir compreender que a sexualidade de uma pessoa não está ligada ao seu gênero, e que gênero e sexualidade são coisas distintas, uma se relaciona com a forma que o indivíduo se entende para o mundo e para si, a outra é a atração emocional ou física que pode ou não sentir por outras pessoas. Pois, dentre esse leque gigantesco de classificações e subclassificações, ainda se encontram as pessoas assexuadas, que podem pertencer a algum subgrupo LGBT e ainda assim, não sentir atração sexual por ninguém, então se relacionam apenas sentimentalmente. 


\section{Conclusões}

O preconceito cria o estereótipo em cima do que não é padronizado, e na atual sociedade machista e patriarcal na qual estamos inseridos, tudo o que não está conforme o padrão, como homens que vão de encontro à feminilidade, ou mulheres que não fazem questão de possuí-la, tornam-se, automaticamente, vítimas de preconceitos advindos dos estereótipos criados.

Nota-se isso, também, dentro da comunidade LGBT, onde os gays efeminados são estereotipados, desvalorizados e inferiorizados, justamente por possuir traços femininos, por abrir mão de sua masculinidade que automaticamente lhes fariam privilegiados.

Os estereótipos empregados a esses corpos vêm graças a uma estrutura patriarcal machista instituída em nossa sociedade a milhares de anos, e que faz com que todos aqueles corpos que fujam do padrão já pré-estabelecido tenham que sofrer reparação, sendo rotulado ou diminuído pela sociedade.

Com vistas ao exposto, nos salta aos olhos que a "raiz" do preconceito está no feminino. Não importa quem seja o sujeito, o que realmente é fundamental, nesses casos é a demonstração da feminilidade, não é a pessoa o problema do preconceito, mas sim seus traços, atitude e qualquer outra questão que componha o que socialmente conhecemos como sendo próprio de uma mulher, ou seja, a classe mais baixa da sociedade em todos os tempos, como afirma Aristóteles (2008) "Quanto ao sexo, a diferença é indelével: qualquer que seja a idade da mulher, o homem deve conservar sua superioridade.”, também podemos apontar isso nas Leis de Mапи (200 a.C) "Uma mulher está sob a guarda de seu pai, durante a infância, sob a guarda de seu marido durante a juventude, sob a guarda de seus filhos em sua velhice; ela não deve jamais se conduzir à sua vontade".

Queremos, com este trabalho, desmistificar estereótipos empregados a homossexuais que acaba por enquadrá-los em identidades que não necessariamente correspondem à realidade. Ao quebrar padrões sociais, visamos desconstruir também preconceitos que por ser tão retrógrados, atrasam o avanço da sociedade em vários aspectos, sejam morais, ou até mesmo legais, pois do ponto de vista da moral, por exemplo, não podemos mais admitir uma sociedade LGBTfóbica com tanta desigualdade e discriminação, e no que se refere a termos legais, também já é inadmissível que um país, o qual deveria ser laico, fomente projetos de leis que se embasem em conceitos religiosos, que normalmente prejudicam a comunidade LGBT, querendo, se não extingui-la, no mínimo apagar a sua existência perante o Estado. Com todo o exposto, procuramos refletir sobre estas questões, problematizando o que aprendemos em nossas casas e escolas desde crianças e desnaturalizando o que nos é imposto 
ao nascer, imaginamos que a escrita deste trabalho pode contribuir para uma sociedade com mais equidade.

\section{Referências}

ARISTÓTELES. A Poética. Lisboa: Edição da Fundação Calouste Gulbenkian, 2008.

BOLSONI, Betania Vicensi. O cuidado de si e o corpo em Michel Foucault: perspectivas para uma educação corporal não instrumentalizadora. SEMINÁRIO DE PESQUISA EM EDUCAÇÃO DA REGIÃO SUL, v. 9, 2012.

GOELLNER, S.V. A produção cultural do corpo. In: Corpo, Gênero e sexualidade: um debate contemporâneo na educação. LOURO, G. L., FELIE, J. GOELLNER, S. V. 4. Ed. Petropolis RJ: Vozes, 2008.

HALL, Stuart. Quem precisa de identidade? In: SILVA, Tomaz Tadeu da (org.). Identidade e diferença: a perspectiva dos estudos culturais. Petrópolis, RJ: Vozes, 2000, p. 103-133.

MANUSRTI - CÓDIGO DE MANU ( 200 A.C. E 200 D.C.). Livro nono: XIX- dos deveres do marido e da mulher, Art. $420^{\circ}$. Disponível em:< http://www.dhnet.org.br/direitos/anthist/manusrti3.htm>. Acesso em: 09 de outubro de 2016.

SILVA JÚNIOR, Jorge Luiz da. GUEI: nem comédia nem drama, um programa de TV contra o preconceito. Juiz de Fora: UFJF; Facom, 2. sem. 2004, 97 f. Projeto Experimental do Curso de Comunicação Social.

REVEL, Judith. Michel Foucault: conceitos essenciais. Tradução Maria do Rosario Gregolin, Nilton Milanez, Carlos Piovesani. - São Paulo: Claraluz, 2005. 